\title{
Reported occupational respiratory diseases in Catalonia
}

\author{
R Orriols, R Costa, M Albanell, C Alberti, J Castejon, E Monso, R Panades, N Rubira, J-P Zock, \\ members of the Malaltia Ocupacional Respiratòria (MOR) Group
}

Occup Environ Med 2006;63:255-260. doi: 10.1136/oem.2005.022525

See end of article for authors' affiliations

.......................

Correspondence to: Dr R Orriols Martínez, Servei de Pneumologia, Hospital Universitari Vall d'Hebron, Passeig Vall d'Hebron, 119-129, 08035 Barcelona, Spain; rorriols@vhebron.net

Accepted

9 November 2005

\begin{abstract}
Objectives: A voluntary surveillance system was implemented in Catalonia (Spain) to ascertain the feasibility, incidence, and characteristics of occupational respiratory diseases and compare them with those of the compulsory official system.

Methods: In 2002, in collaboration with the Occupational and Thoracic Societies of Catalonia, occupational and chest physicians and other specialists were invited to report, on a bimonthly basis, newly diagnosed cases of occupational respiratory diseases. Information requested on each case included diagnosis, age, sex, place of residence, occupation, suspected agent, and physician's opinion on the likelihood that the condition was work related. Compulsory official system data derived from statistics on work related diseases for possible disability benefits declared by insurance companies, which are responsible for declaring these diseases to the Autonomous Government of Catalonia.

Results: Of 142 physicians seeing patients with occupational respiratory diseases approached, 102 (74\%) participated. Three hundred and fifty nine cases were reported, of which asthma $(48.5 \%)$, asbestos related diseases $(14.5 \%)$, and acute inhalations $(12.8 \%)$ were the most common. Physicians rated $63 \%$ of suspected cases as highly likely, $28 \%$ as likely, and $8 \%$ as low likelihood. The most frequent suspected agents reported for asthma were isocyanates $(15.5 \%)$, persulphates $(12.1 \%)$, and cleaning products $(8.6 \%)$. Mesothelioma (5.9\%) was the most frequent diagnosis among asbestos related diseases. The number of acute inhalations reported was high, with metal industries $(26 \%)$, cleaning services $(22 \%)$, and chemical industries (13\%) being the most frequently involved. The frequency of occupational respiratory diseases recorded by this voluntary surveillance system was four times higher than that reported by the compulsory official system.

Conclusions: The compulsory scheme for reporting occupational lung diseases is seriously underreporting in Catalonia. A surveillance programme based on voluntary reporting by physicians may provide better understanding of the incidence and characteristics of these diseases. Persulphates and cleaning products, besides isocyanates, were the most reported causes of occupational asthma. Metal industries and cleaning services were the occupations most frequently involved in acute inhalations with a remarkably high incidence in our register.
\end{abstract}

in n occupational medicine, it is essential to have adequate information on both individual cases and outbreaks of a particular disease for preventive measures to be taken. This aspect is highly important because it permits measures and strategies of action to be sought to prevent the appearance of new cases. ${ }^{1}$ The means established to develop this preventive policy in Catalonia come from statistics on work related diseases for possible disability benefits. ${ }^{2}$ There is clear evidence that these means fail to achieve the desired aims and that information is lacking on the incidence of occupational respiratory diseases. ${ }^{3}$ In fact, occupational respiratory diseases are frequently detected in primary health care and specialised health centres. ${ }^{4}$ In other countries, alternative notification systems based on reports from physicians, experts in occupational respiratory disease, have been brought into force. This type of surveillance was first established in the United Kingdom, which implemented a disease registration system where the notifiers were chest physicians and specialists in occupational medicine. ${ }^{5}$ Following the UK, other similar systems have been started in different countries. ${ }^{6-8}$ These new surveillance systems have confirmed the underestimation of pre-existing data, compiled almost always from compensation or incapacity registers.

The aim of this study was to divulge data obtained in Catalonia following the implementation of an alternative registry system based on voluntary notification by physicians of different specialities.

\section{MATERIAL AND METHODS Reporting physicians}

Six hundred letters were sent to all physicians of the Occupational Medicine Society, 250 to physicians of the Pneumology Society, and 150 to other physicians who could be interested in occupational respiratory diseases (allergologists, general practitioners, internal medicine, and other physicians). Moreover, to maximise participation, the protocol was also presented at Catalan meetings. Physicians who finally agreed to participate in the study as notifiers were instructed to report cases of occupational respiratory disease every two months. The 12 month notification period ran from I January 2002 to 31 December 2002. In Catalonia, employed workers with possible occupational respiratory disease are seen by occupational physicians contracted by insurance companies, which should confirm and declare all these cases to the Department of Labor of the Autonomous Government of Catalonia. ${ }^{2}$ Moreover, the Department of Labor has six regional labour health services which cover almost all Catalonia to attend to any worker whose occupational health problem has not been solved. Selfemployed workers are attended usually treated by the Public Health Service.

\section{Methods of notification}

Notifying physicians were instructed at a meeting on how to fill in the notification forms and how to return them. Every 


\begin{tabular}{|c|c|c|c|c|c|c|c|}
\hline \multirow[b]{2}{*}{ Diagnosis } & \multicolumn{2}{|c|}{ Cases } & \multirow[b]{2}{*}{ Mean age } & \multicolumn{2}{|l|}{ Men } & \multicolumn{2}{|c|}{ Women } \\
\hline & $\mathbf{n}$ & $\%$ & & $\mathbf{n}$ & $\%$ & $\mathbf{n}$ & $\%$ \\
\hline Asthma & 174 & 48.5 & 41.6 & 94 & 54.0 & 80 & 46.0 \\
\hline Acute inhalation & 46 & 12.8 & 35.1 & 27 & 58.7 & 19 & 41.3 \\
\hline Mesothelioma & 21 & 5.9 & 59.4 & 19 & 90.5 & 2 & 9.5 \\
\hline Asbestosis & 18 & 5.0 & 63 & 16 & 88.9 & 2 & 11.1 \\
\hline Pneumoconiosis & 17 & 4.7 & 62.8 & 16 & 94.1 & 1 & 5.9 \\
\hline Benign pleural disease & 12 & 3.3 & 63.8 & 11 & 91.7 & 1 & 8.3 \\
\hline Chronic bronchitis & 10 & 2.8 & 50 & 10 & 100 & 0 & 0 \\
\hline Allergic alveolitis & 6 & 1.7 & 48.3 & 4 & 66.7 & 2 & 33.3 \\
\hline Infectious disease & 5 & 1.4 & 37 & 3 & 60 & 2 & 40 \\
\hline Asthma-like disorder & 4 & 1.1 & 43 & 4 & 100 & 0 & 0 \\
\hline Building related disease & 3 & 0.8 & 22 & 0 & 0 & 3 & 100 \\
\hline Lung cancer & 1 & 0.3 & 53 & 1 & 100 & 0 & 0 \\
\hline Other & 42 & 11.7 & 40.7 & 28 & 66.7 & 14 & 33.3 \\
\hline All reports & 359 & 100 & 47.7 & 233 & 64.9 & 126 & 35.1 \\
\hline
\end{tabular}

two months, they were sent a summary of the cases declared in that two month period and an update of all cases received during the year. Similarly, professionals who failed to reply were sent a reminder. If clarifications were required, they were requested within 15 days of the notification. Only incident cases-those that had not been diagnosed previously-had to be included in the notification form. The following data were obtained for each case: sex, age, smoking status, place of residence, occupation, suspected causal agent, and degree of probability of the suspected diagnosis expressed as very likely, likely, or not very likely. Smoking was divided into the following categories: non-smoker, smoker of less than 20 packs/year, smoker of 20-60 packs/ year, smoker of more than 60 packs/year, pipe or cigar smoker, and ex-smoker of more than one year. Finally, the patients' initials and date of birth were required to avoid duplication of cases. A second meeting was held three months after initiation of the study to dispel any doubts, and another at nine months to discuss the results of the first six months. Daily contact by telephone was made available.

\section{Statistical analyses}

The labour force in Catalonia in 2002 comprised 2253783 workers. Data from surveys of the occupationally active population conducted by the Spanish National Institute of Statistics for the second trimester of 2002 were used to estimate incidence rates in the working population. ${ }^{9}$ As the number of cases was low for certain diseases, all confidence intervals pertaining to incidence rates were calculated using a binomial distribution. When no cases were reported for a certain diagnostic group, the one-sided $97.5 \%$ upper confidence limit was calculated. Data obtained by the Department of Labor of the Autonomous Government of Catalonia from the current official system, based on compulsory notification by the insurance company, were compared with those obtained by this voluntary surveillance programme. ${ }^{10}$

\section{RESULTS}

\section{Reporting system}

One hundred and forty two (14.2\%) physicians to whom the information was given reported that they attended to patients with occupational respiratory disease in their daily practice. Sixty seven $(47 \%)$ of these physicians were specialists in occupational medicine, $33(23 \%)$ pneumologists, and 42 $(30 \%)$ of other specialities.

One hundred and five (74\%) of these 142 physicians agreed to become notifiers; among these, 52 (49.5\%) were occupational medicine specialists, $32(30.5 \%)$ chest physicians, and $21(20 \%)$ professionals of other specialities. The insurance companies, for which at least one of the notifiers worked, covered approximately $80 \%$ of all employed workers in Catalonia. Moreover, at least one of the notifying physicians worked in each of the six regional occupational health services. Finally, at least one notifier worked in practically all the university hospitals of the Public Health Service. A mean of 70 (67\%) physicians returned the notification form bimonthly, although considerable variation existed among notifiers: 36 (34\%) physicians notified less than $10 \%$ and $58(55 \%)$ at least $90 \%$ of the two month periods. Five $(4.8 \%)$ physicians failed to report. A significant variation also existed in the number of cases notified by each physician: five $(4.8 \%)$ physicians notified $168(47 \%)$ cases and $10(9.5 \%)$ notified 229 (64\%).

In the first two month period, 81 notifications and 57 cases were declared; in the second, 75 notifications and 74 cases; in the third, 73 notifications and 60 cases; in the fourth, 47 notifications and 32 cases; in the fifth, 69 notifications and 62 cases; and in the sixth, 75 notifications and 74 cases. Forty two per cent of cases were reported by specialists in occupational medicine, $40 \%$ by pneumologists, and $8 \%$ by other specialists.

\section{Case characteristics}

Three hundred and fifty nine new cases of occupational lung disease were reported (table 1). The overall incidence was 159.3 per million person-years of the working population (table 2). Although male sex predominated in practically all categories, the incidence rate in men was proportionally higher in diagnostic categories with longer latency periods such as mesothelioma, asbestosis, benign pleural disease, pneumoconiosis, and chronic bronchitis than in other categories with shorter latency periods. Mean age was also higher in the diagnostic categories with longer latency periods. Thus, categories with shorter latency periods such as asthma, acute inhalations, sick building syndrome, or bronchopulmonary infection did not exceed a mean age of 45 years, while cases of mesothelioma, asbestosis, pneumoconiosis, asbestos related non-malignant pleural disease, chronic bronchitis, and lung cancer reached a mean age of 50 years.

Although the proportion of smokers among diagnostic categories was variable, the mean of current smokers among all cases was $27 \%$, somewhat lower than the average $(37 \%)$ of the population of working age in Catalonia. ${ }^{11}$ The difference between the proportion of ex-smokers and smokers was 
Table 2 Annual rates by diagnostic group

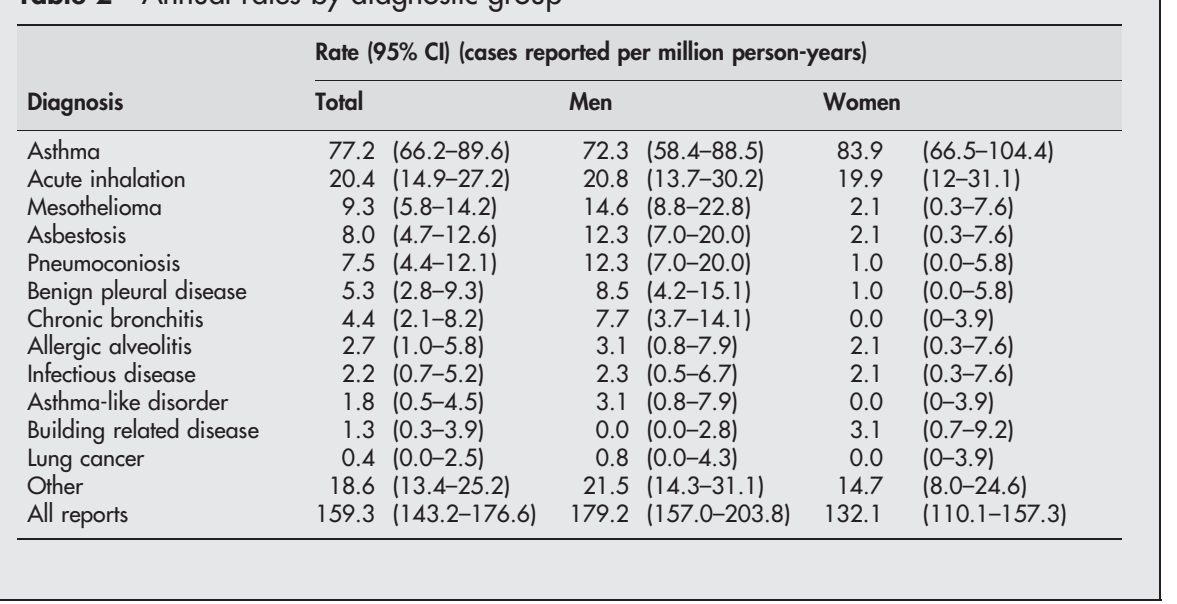

greater in diagnostic categories corresponding to chronic diseases such as asbestosis ( $50 \%$ and $24 \%$, respectively) and pneumoconiosis (53\% and $24 \%$, respectively) than in those corresponding to acute or subacute diseases such as acute inhalation $(4.3 \%$ and $52 \%$, respectively) and occupational asthma (25\% and $21 \%$, respectively). Diagnosis was considered as not very likely in only $8 \%$ of cases. Asthma, asbestos related diseases, and acute inhalation were the most often reported diagnoses.

\section{Occupational asthma}

One hundred and seventy four $(48.5 \%)$ cases were reported, which represents the largest diagnostic group. A higher proportion of women was observed than in other diagnostic groups, except for sick building syndrome in which only three female cases were reported. Only $21 \%$ of patients with occupational asthma were smokers. The causes of occupational asthma were diverse, although isocyanates (15.5\%), persulphates $(12.1 \%)$, cleaning products $(8.6 \%)$, and other chemical products (16.7\%) were the most frequent (table 3 ). Occupation specific rates amounted to 4.9 per million personyears for white-collar workers, 96 for cleaners, and 108 for hairdressers.

\section{Asbestos related diseases}

Fifty two (14.5\%) cases were reported: 21 (5.9\%) corresponded to mesothelioma, $18(5 \%)$ asbestosis, $12(3.3 \%)$ benign pleural disease, and one $(0.3 \%)$ bronchopulmonary cancer. Whereas asbestosis was frequently reported in large companies using asbestos as a raw material, such as

Table 3 Suspected agents in reported occupational asthma cases $(n=174)$

\begin{tabular}{lll}
\hline Agent & Number of cases & \% of cases \\
\hline Isocyanates & 27 & 15.5 \\
Persulphates & 21 & 12.1 \\
Cleaning products & 15 & 8.6 \\
Wood dust & 14 & 8.0 \\
Flour & 13 & 7.5 \\
Latex & 12 & 6.9 \\
Glues and resins & 8 & 4.6 \\
Animal products & 7 & 4.0 \\
Colophony & 7 & 4.0 \\
Grain & 4 & 2.3 \\
Aldehydes & 4 & 2.3 \\
Other chemical products & 29 & 16.7 \\
Other agents & 9 & 5.2 \\
Not identified & 4 & 2.3 \\
\hline
\end{tabular}

fibrocement or brake industries (13/18 cases; $72.2 \%$ ), mesothelioma in this type of company was less frequent (3/ 21 cases; $14.3 \%$ ) and occurred particularly in self-employed workers or those of small companies such as electricians, sheet metal workers, mechanics, and so on.

\section{Acute inhalations}

Forty six $(12.8 \%)$ patients presenting respiratory symptoms following an acute inhalation were recorded. Nine occupational physicians reported $39(85 \%)$ cases and three chest physicians seven (15\%) cases. The mean age, 35.1 years, was one of the lowest in all diagnostic categories. Unlike other diseases, $52 \%$ of patients were smokers. Occupations most frequently related to acute inhalations were those associated with cleaning ( $26 \%$ of cases), the metallurgic industry $(22 \%)$, and the chemical industry (13\%). While acute inhalations related to cleaning were slightly more frequent in women $(7 / 12,58 \%)$, those related to the metal industry were much more frequent in men $(9 / 10,90 \%)$. The rate of work related diseases in cleaners, taking into account occupational asthma and acute inhalations, was 199 per million person-years.

\section{Other diagnostic categories}

The 17 cases of pneumoconiosis were associated with occupations such as mining, founding, or metal polishing. One 31 year old man worked in sandblasting. Regarding the other diagnostic categories, the percentage of smokers was one of the lowest $(24 \%)$ and that of ex-smokers the highest $(52.9 \%)$. Ten cases of chronic bronchitis were related to the work environment; four worked in the metallurgic industry, three with livestock, two in the chemical industry, and one in the automobile industry. The six cases of extrinsic allergic alveolitis included two with espartosis, two caused by fungi, and two due to isocyanates. Five cases of bronchopulmonary infection of occupational origin were declared. Causal agents of the infection were Mycobacterium tuberculosis in two cases and Legionella pneumophila in three. In the other diagnostic category, 17 cases $(4.7 \%)$ corresponded to rhinitis, eight of which were reported by allergologists.

\section{Cases reported by companies to the Compulsory Official Register}

Ninety nine new cases of occupational lung diseases were reported in Catalonia in 2002 according to the board's official statistics, which represents a rate of $44.4 /$ million/year of the working population. Diagnoses associated with these cases were distributed as follows: $42(42 \%)$ asthma, 15 (15.1\%) infections, nine $(9.1 \%)$ acute inhalations, nine $(9.1 \%)$ 
bronchitis, three $(3 \%)$ diseases related to asbestos, and 15 (15.1\%) other diseases.

\section{DISCUSSION}

Information on the registry was provided in a general and not selective manner to all physicians who would hypothetically be interested in occupational respiratory diseases to avoid the exclusion of a possible notifier. This could explain, in part, why only $14.2 \%$ of physicians replied that they attended to patients with occupational respiratory diseases in their daily practice. Comparison of this figure with those found in other registers is difficult because recruitment in the latter was generally more selective. In Quebec, for example, only physicians who attended to occupational respiratory cases were contacted. ${ }^{6}$ Moreover, it is also possible that some physicians who only occasionally suspect this type of disease might refer the patient to a more expert colleague for the disease to be diagnosed and notified. However, the degree of participation in the voluntary notification system in Catalonia can be considered satisfactory because $74 \%$ of specialists who reported that they attended to patients with occupational respiratory diseases later agreed to be notifiers and $67 \%$ notified on all occasions. This proportion is similar to response rates of the registry in the UK and Quebec (Canada) which were $63 \%$ and $68 \%$, respectively, ${ }^{56}$ and higher than that of British Columbia (Canada) which was $38 \%^{7}$ during the early years of operation. The proportion of pneumologist notifiers in relation to other specialists may also seem low compared with that of other registries. ${ }^{5-7}$ This may be due to the fact that, in Catalonia, the prevention and health care of the majority of workers with possible occupational diseases must be provided by a system based on insurance companies in which this kind of work is carried out by occupational, not chest, physicians.

The majority of workers in Catalonia were reasonably covered by the notifying physicians who worked in the insurance companies, regional labour health services, and university hospitals. However, underreporting can be expected, as appears to occur in other similar surveillance systems ${ }^{5-7}$ Not all workers with work related symptoms see a doctor and a work related cause is not always considered or reported. The notification level throughout the year remained stable except during the two months of July and August when there was a decrease attributable to the vacation period in Catalonia. In our setting, many physicians directly refer this type of patient to colleagues considered to be of referral for the assessment of compensation or incapacity, or experts in the diagnosis of this type of disease. This may explain why cases were notified more frequently by some physicians, as also occurred with other registries. ${ }^{6}{ }^{12}$ We did not observe a decline in notifications over time, as has occurred in other registries. ${ }^{7}$ We believe that the assured confidentiality of the system and rapid feedback of available information were essential to achieve adequate participant collaboration.

A total of 359 new cases of occupational lung diseases were reported in 2002, yielding an annual rate of 159 per million. The possibility of cases being reported via more than one route is unlikely as patients' initials and other data are recorded, rendering duplication difficult. This rate is somewhat lower than the 181/million/year reported by the British Columbia Register, ${ }^{7}$ but higher than the 84/million/year reported by the SWORD project $^{5}$ in their early years of operation. However, comparison of registry systems from different countries should be made with caution. The studied population, and also other factors such as compensation systems and specialisation of reporting physicians, could be factors that influence the incidence and characteristics of the reported cases. ${ }^{6}$
The finding of older age in workers with occupational respiratory diseases of longer latency periods seems logical because, in these cases, the disease only becomes manifest after a longer period of time than other diseases with shorter latency periods. On the other hand, the lower incidence of smokers among workers with occupational respiratory diseases compared to the rest of workers in Catalonia could be due to the fact that some had stopped smoking or had not started owing to their health problem. Thus, the difference between exsmokers and smokers and diseases with longer latency periods versus those with shorter latency periods could be due to the fact that symptoms in the longer latency group usually appear more gradually, thereby motivating cessation of smoking.

Asthma is, in general, the most commonly notified occupational respiratory disease in developed countries. ${ }^{4}{ }^{6}$ The high incidence of this disease has been attributed in part to the fact that the entity is easily recognisable by physicians and also that more and more products capable of sensitising the exposed population are entering the market..$^{13}$ In our registry, 174 new cases-almost half of the cases of occupational lung diseases notified-were asthma, which yields a rate of 77.2/million/year. Compared with the first year of operation of other registries, our figures are somewhat lower than those reported in British Columbia in $1991^{\circ}$ and in Quebec in 1992-93, ${ }^{6}$ but higher than those of the UK in 1989. It should also be mentioned that the cause of occupational asthma was not demonstrated by objective tests in all cases notified. Thus, the tendency to impute asthma to one cause, that which more frequently appears to produce occupational asthma in a given occupation or industry, may influence the aetiology reported. As in other registries, isocyanates were the most commonly suspected agents. ${ }^{58}$ However, western red cedar in British Columbia $(\text { Canada })^{7}$ and flour in France, ${ }^{14}$ respectively, were reported more often than isocyanates. The high proportion (12\%) and rate (108/million/year) in our registry of occupational asthma in hairdressers were also noteworthy, and also observed in other countries. ${ }^{15-18}$ Our findings are consistent with the results of a population based study in Spain which observed an increased risk of occupational asthma in hairdressers (OR 1.94; 95\% CI 0.86 to 4.39$).{ }^{19}$ Nevertheless, occupational asthma caused by hairdressing products has been less frequently notified in other registries-for example, only $0.6 \%$ in the Midland Society's Rare Respiratory Disease Registry Surveillance Scheme SHIELD ${ }^{20}$ and $1 \%$ in SWORD. ${ }^{5}$ Further, a high proportion $(8.6 \%)$ and rate (96 per million per year) of occupational asthma were reported to be due to cleaning products, as in other countries, ${ }^{16}{ }^{17} 21$ but in contrast to other previous registries. In SWORD, ${ }^{12}$ only $1.3 \%$ of occupational asthma cases were reported to be due to cleaning products, and in other registries this aetiology was not even mentioned. ${ }^{67}$ The appearance and rising incidence of these two aetiologies could be the result of various factors. More exposed workers may exist and either new products used or old products used in a different manner. On the other hand, regarding working activities usually carried out by self-employed workers, it could have been difficult to detect because preventive controls do not always exist in these subjects as they are not covered by insurance companies in many countries. Moreover, selfemployed workers are usually reluctant to report work related diseases for fear of losing their job. It is also a fact that, in recent years, these causes of occupational asthma, particularly cleaning products, have been studied and mentioned with greater frequency in the medical literature. ${ }^{22-25}$ These facts could explain why, in the past, they were not notified or why few cases of asthma in hairdressers or cleaners were reported compared with more recent registries.

Our data on asbestos related diseases are similar to those reported in Quebec ${ }^{6}$ and lower than those reported in British Columbia $^{7}$ and the $\mathrm{UK}^{5}$ during their early years of operation. 


\section{Main messages}

- The compulsory system for reporting occupational lung diseases is seriously underreported to in Catalonia.

- A voluntary surveillance programme may be more efficient.

- Occupational asthma and acute inhalations were the most common occupational respiratory diseases reported.

- Isocyanates, persulphates, and cleaning products were the most frequent causal agents of occupational asthma.

- Occupations more frequently implicated in acute inhalations were those related to cleaning and the metal industry.

However, as in the latter country, ${ }^{5}$ mesothelioma was the most frequently diagnosed asbestos related disease.

While asbestosis was generally reported in large companies using asbestos as raw material, mesothelioma was produced particularly in self-employed workers or workers of small companies.

The percentage $(12.8 \%)$ and rate (20.4/million/year) of acute inhalations reported in our registry are higher than those of other registries in the early years of operation..$^{5-7} 12$ This could be due to the existence of a higher number of occupational accidents in our country, or simply to their greater notification. Firstly, the number of occupational physicians participating in our registry was higher than that of chest physicians and, both in our study and in others, ${ }^{12}$ occupational physicians were the main source of information on inhalation accidents. Secondly, in our health system, occupational accidents are referred more to labour insurance companies than to the general health service. It is possible, therefore, that notification of these cases is higher because occupational physicians are related to the register, while emergency physicians of the general health system are not. In contrast to reported cases of chronic diseases, mean age for acute inhalations was lower and the percentage of smokers was high $(52 \%)$, a figure which surpassed the mean of smokers in the working population of the same age $(37 \%)$ in Catalonia. ${ }^{11}$ Occupations more frequently implicated in acute inhalations were those related to cleaning and occurred more often in women, and in the metal industry more predominantly in men. Our findings are consistent with those in Spain ${ }^{19}$ and Finland, ${ }^{26}$ which showed an increased risk of asthma among male metal and female cleaning workers.

A report of pneumoconiosis in a 31 year old man involved in sandblasting activities highlights the importance of preventive measures even today in this type of occupation. Rhinitis, which does not usually cause incapacity to work, is not usually a cause notifiable by occupational physicians of insurance companies. For this reason, many patients with rhinitis are treated by allergologists in Catalonia.

The voluntary registry appears to be more efficient than the existing obligatory official system in Catalonia. In fact, the number of reported cases was four times higher than that reported by the official register. This suggests that a significant number of workers with occupational respiratory diseases are incorrectly not covered by a compensation system in Catalonia. Cleaning work may have a significant public health impact because cleaning products and services were reported very frequently in occupational asthma and acute inhalations-the most diagnosed conditions in our registry.

\section{Policy implications}

- It is necessary to improve the current surveillance system in Catalonia.

- Primary preventive measures need to be taken to prevent occupational asthma caused by isocyanates, persulphates, and cleaning products.

- Primary preventive measures need to be taken to prevent acute inhalations in Catalonia.

\section{ACKNOWLEDGEMENTS}

The authors gratefully acknowledge contributions to this project by the participating physicians, and Núria Catot (Pompeu Fabra University) and Estel Plana (IMIM) for statistical assistance. The authors also thank Christine O'Hara for the translation of the report.

\section{Authors' affiliations}

R Orriols, R Costa, E Monso, Societat Catalana de Pneumologia, Catalonia, Spain

M Albanell, C Alberti, J Castejon, R Panades, J-P Zock, Societat Catalana de Medicina del Treball, Catalonia, Spain N Rubira, Societat Catalana d'Allèrgia, Catalonia, Spain

This work was supported by grants from the Fundació Catalana de Pneumologia, Sociedad Española de Neumología y Cirugía Torácica, Red Respira-ISCiii-RTIC-03/11 and by Mutua Asepeyo de Barcelona.

Members of the Malalties Ocupacionals Respiratories Group: Alonso M, Armengol V, Armengol J, Bergua A, Campà MT, Cardona MV, Cayla JA, Colom MC, Cortes I, Cortijo MM, Drobnic ME, Escriche J, Esplugas J, Ferrer J, Fite E, Garcia R, Hernandez S, Leon C, Llobet J, Llorens MT, Magarolas R, Majo J, Marin A, Morell F, Muñoz X, Muñoz J, Navarrom JM, Prat J, Pujol J, Quintana J, Ribas J, Ripoll M, Roger A, Roger N, Rosell A, Sala J, Sanz P, Serrano RM, Such JJ, Such P, Torres MC, Vallmajo $N$, Vendrell $M$, Vilardell $M$, Vink $R$.

\section{REFERENCES}

1 Rosenstock L, Rest KM, Benson JA Jr, et al. Occupational and environmental medicine. Meeting the growing need for clinical services. N Engl J Med $1991: 325: 924-7$

2 Ley $31 / 1995$, de 8 de noviembre, de prevención de riesgos laborales. BOE no 269, de 10 de noviembre, 1995

3 Beckett WS. Occupational respiratory diseases. New Engl J Med 2000;342:406-13.

4 Ross DJ. Ten years of the SWORD project. Surveillance of work-related and occupational respiratory disease. Clin Exp Allergy 1999;29:750-3

5 Meredith SK, Taylor VM, McDonald JC. Occupational respiratory disease in the United Kingdom 1989: a report of the British Thoracic Society and the Society of Occupational Medicine by the SWORD project group. Br J Ind Med $1991 ; 48: 292-8$.

6 Provencher S, Labrèche FP, De Guire L. Physician-based surveillance system for occupational respiratory diseases: the experience of PROPULSE, Quebec, Canada. Occup Environ Med 1997;54:272-6.

7 Contreras GR, Rousseau R, Chan-Yeung M. Occupational respiratory diseases in British Columbia, Canada, in 1991. Occup Environ Med 1994:51:710-12.

8 Baker EL. Sentinel Event Notification System for Occupational Risks (SENSOR): the concept. Am J Public Health 1989;79(Suppl): 18-20.

9 Instituto Nacional de Estadistica. Encuesta de Poblacion Activa. Available at http://www.ine.es/docutrab/epa02_infortec/epa02_infortec.htm [in Spanish] (accessed December 2005).

10 Generalitat de Catalunya. Departament de Treball i Indústria. Sinistralitat Laboral a Catalunya Any 2002. Collecció Prevenció de Riscos Laborals.

11 L'hàbit tabàquic a Catalunya. Departament de Sanitat de la Generalitat de Catalunya. Available at http://www.gencat.net/salut/depsan/units/sanitat/ pdf/poblaciotabac.pdf (accessed December 2005).

12 Meredith SK, McDonald JC. Work-related respiratory disease in the United Kingdom, 1989-1992: report on the SWORD project. Occup Med 1994:44:183-9.

13 Meredith SK, McDonald JC. Occupational asthma in chemical, pharmaceutical and plastic processors and manufacturers in the UK 1989-90. Ann Occup Hyg 1994;38:833-7. 
14 Kopferschmitt-Kubler MC, Ameille J, Popin E, et al. Occupational asthma in France: a 1-yr report of the Observatoire National de Asthmes Professionnels project. Eur Respir J 2002;19:84-9.

15 Bena A, DErrico A, Mirabelli D. A system for the active surveillance of occupational bronchial asthma: the results of two years of activity of the PRIOR program. Med Lav 1999;90:556-71.

16 Ameille J, Pauli G, Calastreng-Crinquand A, et al. Reported incidence of occupational asthma in France, 1996-99: the ONAP programme. Occup Environ Med 2003;60:136-41.

17 Karjalainen A, Kurppa K, Virtanen S, et al. Incidence of occupational asthma by occupation and industry in Finland. Am J Ind Med 2000;37:451-8.

18 Torén K. Self-reported rate of occupational asthma in Sweden 1990-2. Occup Environ Med 1996;53:757-61.

19 Kogevinas M, Anto JM, Soriano JB, et al. The risk of asthma attributable to occupational exposures. A population-based study in Spain. Spanish Group of the European Asthma Study. Am J Respir Crit Care Med $1996 ; 154: 137-43$
20 Gannon PFG, Burge PS. The SHIELD scheme in the West Midlands Region United Kingdom. Midland Thoracic Society Research Group. Br J Ind Med 1993;50:791-6.

21 Torén K, Balder B, Brisman J, et al. The risk of asthma in relation to occupational exposures: a case-control study from a Swedish city. Eur Respir J 1999;13:496-501.

22 Zock J-P, Kogevinas M, Sunyer J, et al. Asthma characteristics in cleaning workers, in other risk jobs and office workers. Eur Respir J 2002;20:679-85.

23 Medina-Ramón M, Zock J-P, Kogevinas M, et al. Asthma symptoms in women employed in domestic cleaning: a community-based study. Thorax 2003;58:950-4.

24 Rosenman KD, Reilly MJ, Schill DP, et al. Cleaning products and work-related asthma. J Occup Environ Med 2003:45:556-63.

25 Muñoz X, Cruz MJ, Orriols R, et al. Occupational asthma due to persulphate salts. Diagnosis and follow-up. Chest 2003;123:2124-9.

26 Jaakkola JJ, Piipari R, Jaakkola MS. Occupation and asthma: a populationbased incident case-control study. Am J Epidemiol 2003;158:981-7.

\section{$\mathrm{ECHO}$}

\section{Cardiac deaths follow industrial disaster}

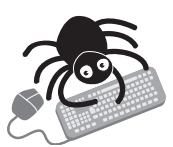

Please visit the Occupational and

Environmental Medicine website [www. occenvmed. com] for a link to the full text of this article. $\mathrm{n}$ industrial disaster increases fatal heart attacks in the immediate aftermath, a one
off study in Tours, France, has confirmed. Cardiologists say that acute stress at the
time and emotional fallout thereafter from, maybe, losing a home and other stressors are likely triggers.

In 2001 an explosion at a chemical plant storing ammonium nitrate in the town left 30 dead and 3000 injured from an earthquake of 3.4 on the Richter scale, which destroyed 27000 homes. Cardiologists could tell whether the disaster provoked more cardiac deaths within a target area of $3 \mathrm{~km}$ radius over what would have been expected otherwise because their incidence had been regularly recorded here since 1985.

Standardised incidence ratios of observed to expected cardiac deaths three days after the explosion were about 3.5 times higher than a mean of two similar periods in 2000 before and after the actual date, and one in 2001 just before. By 10 days the ratios had fallen to twofold or less. This was true regardless of age, sex, history of coronary disease, and whether the cardiac event conformed to a strict or loose definition of acute coronary syndromes. The ratios for people outside the target area were not significantly different three days after the explosion. Nitrogenous compounds released into the atmosphere were thought to be only minor irritants. The target population was 179075 in 2000 and 181944 in 2001 .

A few other studies have linked stressful events with increased cardiac deaths but not in the context of an industrial disaster.

A Ruidavets J-B, et al. Heart 2006:92:257-258. 